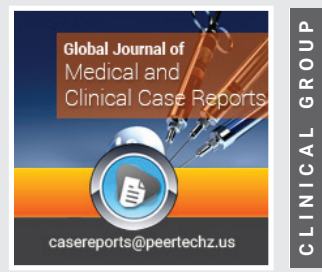

\section{COVID-19 Pandemic: Past, present and future}

\section{Behailu Assefa*}

Department of Veterinary Science, College of Agriculture and Environmental Science, Arsi University,

Asella, Ethiopia
Received: 17 May, 2021

Accepted: 01 June, 2021

Published: 03 June, 2021

*Corresponding author: Behailu Assefa, Department of Veterinary Science, College of Agriculture and Environmental Science, Arsi University, Asella, Ethiopia, Tel: +251 911 839999; E-mail: newbaye@gmail.com

Keywords: Control; Coronavirus; COVID-19; Pandemic; Prevention

https://www.peertechzpublications.com

\begin{abstract}
COVID-19 is the emerged pandemic disease of mankind. This disease yet has no proven therapy. Measures like the use of a vaccine, chemical spray, disinfectants, antiseptics, and supportive therapies could help control this disease that is caused by a coronavirus. Further effective control and prevention measures are urgently demanded to save the life of billions of the world's human population. Especially having effective, and affordable vaccine that can be supplied as per its demand to all humankind is the priority at present.
\end{abstract}

\section{Introduction}

There was no agreed-on primary source of the COVID-19 outbreak that was originated in December 2019. It might not be denied that more probably the origin of this disease was associated with wrong human practices; be it physical, psychological, or behavioral (abstract conducts). From the facts of the universe we are in, one can conclude that in no way, bad things originated from good did. What is wrong with the so-called academicians (including me) is that we are only academicians. But academic performance alone can't make one self-actualize. The perfect human complements the specific profession-based academic knowledge with extra qualities. Knowing social norms, having detailed insights into his immediate and wider environments, insights about the seen and the unseen world, having penetrating views about obstacles in life in this universe, being kind and genuine, and giving value to others are some of the qualities that one should have to at least approach the perfect human. In the absence of these qualities what human beings do always accompanied by problems like the COVID-19, which we are facing globally for the past one and a half years and are still worried about. Not only the emergence but also in the production of the COVID vaccine, its ownership, distribution, and things related to payments, our selfishness is still going on [1].

It may not be much important now to waste time debating on the source of Covid-19 and the risk factors for its emergence. These may not yield any positive impact in terms of measures to be taken to get rid of this pandemic disease. What may be helping is worrying about the source of this disease only in terms of gaining knowledge about the characteristics of the causative agent so that get a hint to develop effective control interventions like having an effective vaccine. Because the primary focus now should be on the solution to control this pandemic. The quality of any individual, particularly those involved in the clinical and medical professions; an organization, or a nation should be measured by the magnitude of an effort they have induced in control of this disease.

The transmission mechanism of the disease is also another aspect that should be thoroughly investigated to come up with a problem-solving solution. The well-perceived transmission of the disease is from the previously infected human or a contaminated environment, particularly materials contaminated by human's infective droplets to a susceptible human. When susceptible human gain access to infected human or contaminated materials or the environment either directly or indirectly, can acquire the virus. Entry of the virus could happen either through the respiratory or oral pathways or through the eye [1]. The aerosol transmission could also occur through droplet nuclei which remain airborne for sufficient time to transmit the pathogen if gains access entry to the respiratory tract [2].

\section{The primary control options}

Any piece of measure in the control of the COVID-19 pandemic should either target the virus causative agent or the 
human host. The first option that is fighting against the virus is, as usual, a 'blind fight' as we can't see the virus to fight within the battle of field. The only option we have in the control method that targets directly fighting the virus is to spray chemicals that potentially kill the virus in the environment or to apply disinfectants on contaminated materials and to wash hands with antiseptics or detergents. All these actions involve a 'blind fight' in which we are not sure whether we properly target the virus and at the same time whether the targeted virus is properly challenged and killed. The only thing that we know at this level is that this method could increase the probability of death of the challenged virus and prevent from having access to a human being. These approaches are exposed to a lot of errors in the application of the chemicals and end up with the corresponding shortcoming. The spray applied on an external environment may also cause a problem to other life on earth, in water or air through its immediate or residual effect. Even the use of the spray isn't economical as it consumes much volume of the chemical. Whatever the case, as far as we have no better option, we were obliged to use these techniques to fight the virus with a recommendation to use them properly with minimum error. This was the case before humans moved onto other control options. Nowadays spraying is not much practiced [3].

The other similar technique targeting the viral causative agent is to apply antimicrobials either biochemical from the virus or medicinal herbs. This needs very intensive experiments and may not safely solve the problem even if it succeeded, particularly the virus-based biochemicals. Biochemicals usually substitute one problem with another problem of lesser or higher consequence. This is because antimicrobials are used in vivo (inside) unlike the spray, disinfectant, or antiseptic chemicals that are applied to the external environment and external body surfaces. As a result of this, they got a chance to react with body cells and may cause negative consequences. The spray chemicals can also have a chance to get in touch with the internal body parts, particularly when safety rules will not be followed while handling and during application. The antimicrobials so far produced were applied either in the form of vaccines, antisera, drugs, or other forms. Recently there are different attempts in the production of vaccines against the disease though all are constrained by supply, efficiency, affordability, sideeffects, and thus acceptance. Still, these methods are the type of 'blind fight' as one is not sure whether the virus is attacked by the used chemical or not, except increasing the chance of the virus being attacked or preventing the virus from gaining access to the body cells and cause disease [4].

Whatever the case, now it is believed that a higher immunity level to SARS-CoV-2 among the human population will be achieved through vaccination instead of natural infection. That is why all attempts regarding control of COVID 19 are directing toward vaccine production and distribution. But vaccines produced so far, though expected to induce immunological protection robustly, do not provide life-long protection against COVID-19 and may require booster doses. Re-infection is reported in COVID-19 and following that the present-day caution is abandoning immunity passports and compliance of mitigation measures by recovered patients as thoroughly as the unexposed population at risk. The residual low antibody titer and $\mathrm{T}$ cell immunity might have increased severity during re-infection [5]. Anyhow, as the world is struggling to cope with coronavirus disease 2019 (COVID-19), the 50\% efficacy threshold was set for COVID-19 vaccines. This is because COVID-19 was deemed such a severe disease, that if a vaccine is only $50 \%$ effective, it's still worth using [6].

The COVID 19 vaccines that have been attempted at different levels for production and distribution are $\mathrm{c}-\mathrm{l}$, Current SARS-CoV-2 vaccine candidates that include inactivated virus vaccines; live-attenuated vaccines; recombinant protein vaccines that are based on the spike protein, the $\mathrm{RBD}$, or on virus-like particles; replication-incompetent vector vaccines; replicationcompetent vector vaccines; inactivated virus vector vaccines that display the spike protein on their surface; DNA vaccines and RNA vaccines [7].

Including the vaccine, all the techniques used in this first approach in the fight against SARSCoronavirus-2 make use of knowledge of the chemical nature of the virus to its molecular level. Anyhow fighting the virus in this regard ranges from fighting the virus at a distance while it is in an open environment away from human personal territory to fighting the virus while it is in the cell of a human being. That is: spray ------- $\rightarrow$ disinfectant ------------ $\rightarrow$ antiseptic---$--\rightarrow$ antimicrobials (drug, vaccine).

\section{Use of masks}

The second option in the fight against COVID-19 is targeting the human host, which is excluding the human from being accessed by the virus. Make a human being inaccessible to a virus mean to let the virus not get an appropriate host to survive in. To devoid the virus of a host, putting fences and obstacles in between is needed. These include physical barriers like masks, gloves, and protective clothes and the use of chemical barriers that make human beings resistant to the virus after immunization by vaccines. Hiding us from the virus is also taken as an alternative to escape this virus. That is why staying home was frequently recommended as a control option for this disease and still applied on some occasions [8].

\section{Early diagnosis}

Sensory approaches like early detection of the virus in an external environment and the body of a human can be taken as a third approach. Diagnosis of the presence of the virus in the environment as well as in the body of human beings is one mandatory action to be taken in the fight against the virus. This is even more reliable than the above-mentioned two approaches because this could create a technique that avoids a 'blind fight' against this virus. Especially, if it is so accurate in detecting the virus, it could create a more logical approach to fight the virus. This needs the invention of very sensitive tools and the development of soft wares to detect the presence of the virus in the environment and on \& in the body of human beings. At least this approach will help to know 
the infected individuals and help to isolate them before they pass the disease agent to others and also to assist the infected individual recover from infection by supportive therapy. This third approach also facilitates all the measures under the remaining two approaches to be conducted under tangible evidence and will make these two approaches very target and effective. The infrared thermometer is the only technology we have at hand at a relatively wider coverage in this regard even if not a hundred percent promising. PCR methods are the second COVID-19 detection method that is gaining momentum to be widely applied though constrained by affordability. Other methods of causative virus isolation are only limited to a few who can deserve to afford it [9].

\section{Supportive therapy}

The last but not the least option in controlling the virus causative agent of COVID-19 is investing in supportive therapies like producing oxygen ventilators and treatments for secondary complications. Supportive therapies are what we do on the verge of our failure trying all the other options. This is an indicator of fading up in the long tiresome fight with the insignificant but winner virus. These therapies are not what we do but need the help of others after we are defeated and taken the upper hand over by the virus. Fail in the one-to-one fight with the virus! The success of these therapies depends on the immune status of the patient, early provision of support, and exceptional power of withstanding the virus challenge [10].

\section{Forwarded comments}

Let us know what we are lacking from its very scratch which looks elementary but basic to cope up with things like COVID-19 and similar problems against which all the collective knowledge of human beings in the universe that was accumulated over centuries can't bring a solution [11]. Let us fight with this virus against which all that human beings have as a first line of defense (a primary immune mechanism), secondary and tertiary immune defense mechanism can't sheath him of this virus. Don't let ourselves feel lonely and helpless standing in the middle of nowhere [12].

\section{References}

1. Behailu A (2021) Transmission and Pathogenesis of Severe Acute Respiratory Syndrome Coronavirus 2. Innovare Journal of Medical Sciences 9: 2-3. Link: https://bit.ly/3fGRAM4

2. Priyanka, Choudhary OP, Singh I, Patra G (2020) Aerosol transmission of SARS-CoV-2: The unresolved paradox. Trav Med Infec Dis 37: 101869. Link: https://bit.ly/3uRsYop

3. Geller C, Varbanov M, Duval RE (2012) Human Coronaviruses: Insights into Environmental Resistance and Its Influence on the Development of New Antiseptic Strategies. Viruses 4: 3044-3068. Link: https://bit.ly/3i93Cj1

4. COVID-19 Scientific Resources Geneva Centre for Education \& Research in Humanitarian Action.

5. Priyanka, Choudhary OP, Singh I (2021) Protective immunity against COVID-19: Unravelling the evidences for humoral vs. cellular components. Travel Med Infect Dis 39: 101911. Link: https://bit.ly/3hHUVMt

6. WHO (2021) WHO Africa. What is COVID-19 vaccine efficacy?

7. Krammer F (2020) SARS-CoV-2 vaccines in development. Nature 586: 516527. Link: https://bit.ly/34FjBNG

8. COVID-19 virtual press conference - 3 April, 2020. World Health Organization Link: https://bit.ly/3ccZ9rH

9. Do vaccines against pneumonia protect you against the new coronavirus? World Health Organization

10. Begley S (2020) With ventilators running out, doctors say the machines are overused for Covid-19.

11. Qian X, Ren R, Wang Y, Guo Y, Fang J, et al. (2020) Fighting against the common enemy of COVID-19: a practice of building a community with a shared future for mankind. Infect Dis Poverty 9: 34. Link: https://bit.ly/3g1jEIT

12. The origin of covid-19 (2020) The pieces of the puzzle of covid-19's origin are coming to light. How they fit together, though, remains mysterious. Science \& Technology. Link: https://econ.st/2S1ZCGI

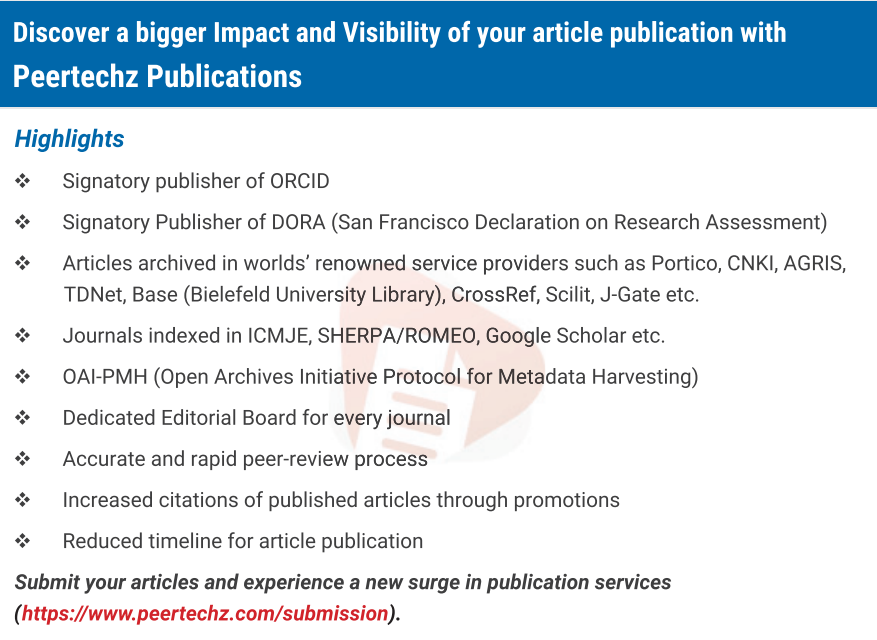

Copyright: (c) 2021 Assefa B. This is an open-access article distributed under the terms of the Creative Commons Attribution License, which permits unrestricted use, distribution, and reproduction in any medium, provided the original author and source are credited. 